\title{
A pilot study on secondhand tobacco exposure: parental knowledge about health impact and feasibility of cessation
}

This article was published in the following Dove Press journal: Drug, Healthcare and Patient Safety

\author{
Hina Walia' \\ Rebecca Miller' \\ Dmitry Tumin' \\ Joseph D Tobias ${ }^{1,2}$ \\ Roby Sebastian ${ }^{1,2}$
}

'Department of Anesthesiology and Pain Medicine, Nationwide Children's Hospital, Columbus, OH, USA;

${ }^{2}$ Department of Anesthesiology, The Ohio State University, Columbus, $\mathrm{OH}$, USA
Correspondence: Hina Walia

Department of Anesthesiology and Pain Medicine, Nationwide Children's Hospital, 700 Children's Drive,

Columbus, OH 43205, USA

$\mathrm{Tel}+\mathrm{I} 6147224192$

Fax + I 6I47224203

Email hina.walia@nationwidechildrens.org
Introduction: As the primary source of smoke exposure is in the home, the smoking behaviors of parents and other caregivers are key determinants of a child's exposure to secondhand smoke. The perioperative period offers an opportunity to discuss smoking cessation strategies. Methods: This prospective study included 97 parents or caregivers of patients undergoing dental surgery. Caregivers were surveyed in the dental waiting room during the preoperative phase. The primary aim was to determine the feasibility of using the preoperative encounter to offer smoking cessation resources to parents of pediatric patients. The secondary aim was to compare willingness to receive smoking cessation resources according to the knowledge of the risks of secondhand smoking (ie, being aware of secondhand smoking and knowing that it posed a risk to their child).

Results: Awareness of risks due to secondhand smoking was $65 \%$ in the overall cohort and $58 \%$ among current smokers ( $P=0.284$ vs nonsmokers). Among smokers in our study, only a small percentage (12\%) were interested in smoking cessation help. Knowledge of the risks of secondhand smoke may not be sufficient for smokers to express willingness to receive help.

Conclusion: The outpatient clinic may be a teaching opportunity for smoking cessation for caregivers. However, we found that only a small percentage of caregivers were interested in receiving information about smoking cessation. This was despite the fact they were aware of the potential adverse effects of secondhand smoke on their children.

Keywords: smoking cessation, caregivers, survey, health impact

\section{Introduction}

One in three children in the USA lives with a tobacco smoker. ${ }^{1}$ As the primary source of smoke exposure is in the home, the smoking behaviors of parents and other caregivers are key determinants of a child's exposure to secondhand smoke. Various adverse effects have been ascribed to secondhand smoke. ${ }^{2}$ The detrimental impact of secondhand smoke on children has been well established. ${ }^{3}$ Children exposed to smoking are more likely to develop respiratory diseases such as asthma, bronchitis, and reactive airway disease. ${ }^{4}$ Children with a history of tobacco exposure who undergo procedures with general anesthesia are at an increased risk of adverse respiratory events in the perioperative period including coughing, breath holding, bronchospasm, laryngospasm, and the rapid development of hypoxemia. ${ }^{5}$

The perioperative period offers an opportunity to discuss how risk factors in the home can be mitigated to improve a child's health. ${ }^{6}$ Heightened awareness of perioperative risks related to a child's smoke exposure may increase caregivers' willingness to 
seek help with smoking cessation if this is discussed around the time a child is scheduled to undergo surgery. ${ }^{7-9}$ We conducted a pilot study to determine the feasibility of using the preoperative encounter as a "teachable moment" for offering smoking cessation resources to the parents of pediatric patients presenting for surgery. Our secondary aim was to investigate whether caregivers' knowledge of risks related to smoke exposure is associated with interest in pursuing smoking cessation.

Table I Study questionnaire

\begin{tabular}{|c|c|}
\hline Question & Answer choices \\
\hline \multicolumn{2}{|l|}{ I. Age (years) } \\
\hline 2. Gender & $\begin{array}{l}\text { A. Male } \\
\text { B. Female }\end{array}$ \\
\hline 3. Are you Hispanic, Latino, or Spanish origin? & $\begin{array}{l}\text { A. Yes } \\
\text { B. No }\end{array}$ \\
\hline 4. Which one or more of the following would you say is your race? & $\begin{array}{l}\text { A. White } \\
\text { B. Black or African American } \\
\text { C. American Indian or Alaska Native } \\
\text { D. Asian or Pacific Islander }\end{array}$ \\
\hline 5. What is the highest level of school you have completed? & $\begin{array}{l}\text { A. Less than high school } \\
\text { B. High school graduate or equivalent } \\
\text { C. Some college or associate degree } \\
\text { D. Bachelor's degree } \\
\text { E. Masters, professional or doctoral degree }\end{array}$ \\
\hline 6. Have you smoked at least 100 cigarettes in your entire life? ${ }^{\mathrm{a}}$ & $\begin{array}{l}\text { A. Yes } \\
\text { B. No }\end{array}$ \\
\hline 7. How often do you now smoke cigarettes? & $\begin{array}{l}\text { A. Everyday } \\
\text { B. Some days } \\
\text { C. Not at all }\end{array}$ \\
\hline $\begin{array}{l}\text { 8. How many people who live in your child's home smoke cigarettes or other tobacco products } \\
\text { inside the home? (number) }\end{array}$ & \\
\hline 9. Has a doctor or other health professional ever told you that your child has asthma? & $\begin{array}{l}\text { A. Yes } \\
\text { B. No }\end{array}$ \\
\hline $\begin{array}{l}\text { 10. Has a doctor or other health professional ever told you that your child had other chronic } \\
\text { breathing problems (chronic cough, chronic runny nose, reactive airway disease, etc.)? }\end{array}$ & $\begin{array}{l}\text { A. Yes } \\
\text { B. No }\end{array}$ \\
\hline II. During the past I 2 months, has your child had three or more ear infections? & $\begin{array}{l}\text { A. Yes } \\
\text { B. No }\end{array}$ \\
\hline 12. Have you heard of secondhand smoke exposure? & $\begin{array}{l}\text { A. Yes } \\
\text { B. No }\end{array}$ \\
\hline $\begin{array}{l}\text { 13. Do you agree or disagree with the following statement: secondhand smoke exposure can } \\
\text { harm your child? }\end{array}$ & $\begin{array}{l}\text { A. Agree } \\
\text { B. Disagree } \\
\text { C. Not sure } \\
\end{array}$ \\
\hline 14. Have you heard of thirdhand smoke exposure? ${ }^{c}$ & $\begin{array}{l}\text { A. Yes } \\
\text { B. No }\end{array}$ \\
\hline $\begin{array}{l}\text { 15. Do you agree or disagree with the following statement: thirdhand smoke exposure can harm } \\
\text { your child? }\end{array}$ & $\begin{array}{l}\text { A. Agree } \\
\text { B. Disagree } \\
\text { C. Not sure } \\
\end{array}$ \\
\hline 16. Have you ever been offered help to stop smoking? & $\begin{array}{l}\text { A. Yes } \\
\text { B. No } \\
\text { C. Not applicable }\end{array}$ \\
\hline 17. Would you be interested in help to stop smoking? & $\begin{array}{l}\text { A. Yes } \\
\text { B. No }\end{array}$ \\
\hline
\end{tabular}

\section{Methods}

This prospective study was approved by the Institutional Review Board of Nationwide Children's Hospital (Columbus, OH, USA). Nationwide Children's Hospital is an urban, free-standing, 510-bed tertiary care children's hospital. The data were collected in the dental waiting room, attached to the main hospital, in the form of a survey in the preoperative phase which was conducted by a research associate while the parents were waiting in the clinic (Table 1). Verbal consent

Notes: alf no, skip to Q8. 'lf no, skip to Q14. If no, skip to Q16. 
was obtained, and an information sheet regarding the study was given to the parents prior to completing the survey. One parent or guardian of a child presenting for dental surgery could complete the survey. The dental surgery center was chosen given that all of the patients are generally healthy (American Society of Anesthesiologists Classification physical status I or II), the environment is non-hurried allowing for ample time to discuss the project with the parents, and the children are presenting for elective, nonlife-threatening surgery. There were no exclusion criteria. A convenience sample of 100 families was planned according to the feasibility of data collection and the lack of reliable a priori data on how many caregivers would be willing to seek help with smoking cessation.

Data were collected on caregiver characteristics including age, gender, ethnicity, and smoking history. Current smokers were defined as those who reported smoking at least 100 cigarettes in their lives and who smoked every day or most days. The primary aim was to determine the feasibility of using the preoperative encounter to offer smoking cessation resources to parents of pediatric patients. The secondary aim was to compare willingness to receive smoking cessation resources according to the knowledge of the risks of secondhand smoking (ie, being aware of secondhand smoking and knowing that it posed a risk to their child).

Categorical variables were expressed as counts and percentages and compared across knowledge of secondhand smoke risk using Fisher's exact test. Continuous variables were expressed as mean with SD and compared across knowledge of secondhand smoke risk using a two-sample $t$-test. For the secondary objective, the association between willingness to receive smoking cessation help and knowledge that secondhand smoke is harmful was analyzed using a Fisher's exact test. Statistical analysis was performed using Stata/IC 14.2 (StataCorp LP, College Station, TX, USA) with two-tailed $P<0.05$ considered statistically significant.

\section{Results}

Three parents were excluded from the analysis for not completing the questionnaire. Of the 97 remaining parents, 43 were classified as current smokers. Awareness of risks due to secondhand smoking was $65 \%$ in the overall cohort and $58 \%$ among current smokers ( $P=0.284$ vs nonsmokers). The awareness of the term "thirdhand smoking" was $9 \%$ in the cohort. For further analysis, one caregiver in the group of current smokers was excluded due to not reporting whether he/she wanted cessation help. Interest in smoking cessation help and caregiver characteristics are summarized in Table 2 according to the current smokers' knowledge of secondhand smoke risk. Of the 43 smokers in this analysis, only five (12\%) stated that they were interested in receiving smoking cessation help. This proportion did not differ according to the knowledge of the risks posed by secondhand smoke ( $P=0.064$ ). In post hoc bivariate analysis, the only study characteristic associated with wanting smoking cessation help was having received no previous help with smoking cessation (four of five among those who wanted help vs nine of 38 among those who did not want help; $P=0.024$ ).

\section{Discussion}

According to the US Surgeon General Report, nearly $60 \%$ of children between the ages of 3 and 11 years in the USA

Table 2 Characteristics and smoking knowledge of smokers according to whether they know the risks of secondhand smoke ( $\mathrm{N}=43$ )

\begin{tabular}{|c|c|c|c|}
\hline \multirow[t]{2}{*}{ Variables } & $\begin{array}{l}\text { Knowledge of risks of } \\
\text { secondhand smoke }(n=25)\end{array}$ & $\begin{array}{l}\text { No knowledge of risks of } \\
\text { secondhand smoke }(n=18)\end{array}$ & \multirow[t]{2}{*}{$P$-value } \\
\hline & n (\%) or mean (SD) & n (\%) or mean (SD) & \\
\hline Willingness to receive smoking cessation help & $5(20 \%)$ & $0(0 \%)$ & 0.064 \\
\hline Has been offered help to quit smoking & $18(72 \%)$ & $12(67 \%)$ & 0.747 \\
\hline Age (years) & $33(8)$ & $29(5)$ & 0.115 \\
\hline Gender: male & $9(36 \%)$ & $9(50 \%)$ & 0.532 \\
\hline \multicolumn{3}{|l|}{ Race } & \multirow[t]{5}{*}{0.223} \\
\hline Hispanic & $0(0 \%)$ & $\mathrm{I}(6 \%)$ & \\
\hline Non-Hispanic White & $20(80 \%)$ & $10(56 \%)$ & \\
\hline Non-Hispanic Black & $4(16 \%)$ & $5(28 \%)$ & \\
\hline Non-Hispanic others & $\mathrm{I}(4 \%)$ & $2(11 \%)$ & \\
\hline \multicolumn{3}{|l|}{ Education } & \multirow[t]{4}{*}{$>0.999$} \\
\hline High school or less & $12(48 \%)$ & $9(50 \%)$ & \\
\hline Some college or associate's degree & $9(36 \%)$ & $7(39 \%)$ & \\
\hline Bachelor's degree or higher & $4(16 \%)$ & $2(11 \%)$ & \\
\hline Child has asthma, chronic breathing conditions, or ear infections & $10(40 \%)$ & $7(39 \%)$ & $>0.999$ \\
\hline Number of people who smoke in child's home & $\mathrm{I}(\mathrm{I})$ & $\mathrm{I}(\mathrm{I})$ & 0.352 \\
\hline
\end{tabular}


are exposed to secondhand smoke. ${ }^{2}$ Addressing this problem with parents is essential to protect these children and prevent the development of complications related to exposure to secondhand smoke. Families whose children present to acute care settings may be particularly receptive to information about smoking cessation. Among adults, providing smoking cessation intervention to emergency department patients has been found to be feasible. ${ }^{10}$ In addition, in adult patients, the preoperative clinic has been shown to be an effective arena for discussion regarding smoking. ${ }^{11-13}$ A prospective, randomized study of 117 adult patients, scheduled to undergo elective orthopedic or general surgery, demonstrated increased smoking cessation in the intervention group with 20 of 55 patients (36\%) refraining from smoking during the perioperative period vs only one of $62(2 \%)$ in the control group $(P<0.001) \cdot{ }^{13}$ After 1 year, those in the intervention group were most likely to continue to refrain from smoking than the control group, $33 \%$ vs $15 \%(P=0.03)$.

Because of the high association between dental caries and secondhand smoke exposure among children and the previous success rates of smoking cessation programs delivered in dental offices, we determined that the dental center would be a good setting for providing smoking cessation resources to parents. ${ }^{14-16}$ In this study, we assessed whether pre-procedure encounters in the dental center outpatient clinic could be a teaching opportunity for smoking cessation for caregivers. We also assessed whether caregivers' knowledge of the health effects of smoking made them more receptive to smoking cessation resources in this setting. Among smokers in our study, only a small percentage $(12 \%)$ were interested in smoking cessation help. Although most smokers acknowledged the risks of secondhand smoke, this did not increase their interest in obtaining smoking cessation help. Knowledge of the risks of secondhand smoke is necessary, but may not be sufficient for being willing to receive help.

There are several potential reasons for this lack of motivation to receive resources for smoking cessation. Caregivers may have already adjusted their smoking habits to their awareness of secondhand smoke risks. Caregivers may believe that choosing not to smoke in the immediate presence of the child is enough to alleviate this risk. Parents frequently state that they smoke outside or do not smoke around their children perhaps indicating that such practices effectively eliminate the risk to their children. In addition, even among caregivers who stated that secondhand smoking can be harmful to their child, they may not perceive the magnitude of the actual harm especially in children with comorbid respiratory diseases such as asthma. Furthermore, caregivers may not be aware of thirdhand smoke, which occurs when residual tobacco smoke contamination remains after a cigarette is extinguished. ${ }^{17}$ Several studies have shown that the harmful components from thirdhand smoke can be found in dust, surfaces, and air in places such as homes, vehicles, and even hospitals. ${ }^{18-20}$ The effects of these compounds can be found in a home up to 2 months after smoking. ${ }^{18}$ In a previous study, $91 \%$ of the cohort agreed that thirdhand smoking is harmful at baseline while $9 \%$ did not agree. ${ }^{21}$ Our study revealed an educational deficit in which only $9 \%$ of the entire cohort reported knowing the terminology "thirdhand smoke". Finally, the question asking if the caregiver was interested in receiving smoking cessation help is a crude indicator of whether the caregiver wants to quit smoking. Rather, it indicates the caregiver's willingness to receive resources in this specific setting. Caregivers who are interested in quitting smoking may not be open to receiving help from the dental center as they may be more concerned about their child's upcoming dental procedure rather than about their own smoking.

Only $58 \%$ of smokers in our study agreed that secondhand smoke could be harmful, much lower than a national study which found that $90 \%$ of smokers recognize that environmental tobacco smoke could be harmful. ${ }^{22}$ Although some of this difference may be caused by decreased familiarity with the term "secondhand smoke", this deficit further suggests that the dental center may be an opportunity to educate parents and providers about the adverse effects of second- and thirdhand smoke.

Even among smokers who were aware of the harm of secondhand smoke in our study, only $20 \%$ expressed a willingness to receive smoking cessation resources. In a survey of smokers in the Minnesota Heart Health Program, more than half of respondents requested to receive smoking cessation resources, regardless of knowledge of the risks of secondhand smoke. ${ }^{23}$ The low percentage of smokers in our study willing to receive smoking cessation resources suggested that knowledge is not sufficient to motivate these parents to quit smoking. ${ }^{24}$ Due to this resistance to smoking cessation help, caregiver education should reinforce that there is no safe level of secondhand smoking exposure.

Surveys have important limitations. Several factors may affect the responses obtained such as topic of the survey, length of the survey, and the place where the survey is administered. Even simple things such as the wording of questions may play a role in the participant's response. ${ }^{25-28}$ The questions used to assess parent's knowledge of risks of secondhand smoke exposure and parent's interest in receiving assistance for smoking may have been interpreted differently by different parents. To ensure that we received unbiased responses, we did not provide any additional encouragement or incentive to the parents or guardians. 


\section{Conclusion}

We noted that a low percentage of parents or guardians who smoke were interested in receiving information regarding smoking cessation during their child's presentation for dental surgery. An awareness of the risks of secondhand smoke did not increase the willingness of caregivers to receive smoking cessation help. Because of the relatively low awareness of secondhand smoke risks among smokers in our sample, the preoperative encounter may be an effective teaching moment to provide and educate parents on these adverse effects of smoking. However, better methods of educating caregivers about the potential side effects of secondhand smoke and of discussing the issue of smoking cessation are still needed. Current guidelines of the American Academy of Pediatrics (AAPs) recognize tobacco use as a pediatric disease, citing the harms caused by tobacco and secondhand smoke exposure and influence of adult tobacco use on pediatric tobacco use, and provide an opportunity for pediatricians to assist patients and families with tobacco use prevention and treatment. Because many parents see their child's clinician more frequently than their own, ${ }^{29}$ the pediatric setting may be an effective time to discuss smoking cessation with parents. However, our pilot study shows that, in the dental office setting, lack of interest in smoking cessation help remains a hurdle for providing smoking cessation resources to parents.

\section{Disclosure}

The authors report no conflicts of interest in this work.

\section{References}

1. King K, Martynenko M, Bergman MH, Liu YH, Winickoff JP, Weitzman M. Family composition and children's exposure to adult smokers in their homes. Pediatrics. 2009;123(4):e559-e564.

2. US Department of Health and Human Services. The Health Consequences of Involuntary Exposure to Tobacco Smoke: A Report of the Surgeon General. Atlanta, GA: US Department of Health and Human Services, Centers for Disease Control and Prevention, Coordinating Center for Health Promotion, National Center for Chronic Disease Prevention and Health Promotion, Office on Smoking and Health; 2006

3. Bek K, Tomaç N, Delibas A, Tuna F, Teziç HT, Sungur M. The effect of passive smoking on pulmonary function during childhood. Postgrad Med J. 1999;75(884):339-341.

4. Lyons B, Frizelle H, Kirby F, Casey W. The effect of passive smoking on the incidence of airway complications in children undergoing general anaesthesia. Anaesthesia. 1996;51(4):324-326.

5. Desoto H, Patel RI, Soliman IE, Hannallah RS. Changes in oxygen saturation following general anesthesia in children with upper respiratory infection signs and symptoms undergoing otolaryngological procedures. Anesthesiology. 1988;68(2):276-278.

6. Nafiu O, Chimbira W. Pediatric preoperative assessment: 6 million missed opportunities for childhood obesity education. 2017.
7. Pearce AC, Jones RM. Smoking and anesthesia: preoperative abstinence and perioperative morbidity. Anesthesiology. 1984;61(5):576-584.

8. Egan TD, Wong KC. Perioperative smoking cessation and anesthesia: a review. J Clin Anesth. 1992;4(1):63-72.

9. Munday IT, Desai PM, Marshall CA, Jones RM, Phillips ML, Rosen M. The effectiveness of pre-operative advice to stop smoking: a prospective controlled trial. Anaesthesia. 1993;48(9):816-818.

10. Simerson D, Hackbarth D. Emergency nurse implementation of the brief smoking-cessation intervention: ask, advise, and refer. $J$ Emerg Nurse. 2017.

11. Sadr Azodi O, Lindström D, Adami J, et al. The efficacy of a smoking cessation programme in patients undergoing elective surgery: a randomised clinical trial. Anaesthesia. 2009;64(3):259-265.

12. Wong J, Abrishami A, Yang Y, et al. A perioperative smoking cessation intervention with varenicline: a double-blind, randomized, placebocontrolled trial. Anesthesiology. 2012;117(4):755-764.

13. Villebro NM, Pedersen T, Møller AM, Tønnesen H. Long-term effects of a preoperative smoking cessation programme. Clin Respir J. 2008;2(3):175-182.

14. Secker-Walker RH, Solomon LJ, Haugh LD, et al. Smoking cessation advice delivered by the dental hygienist. A pilot study. Dent Hyg. 1988;62(4):186-192.

15. Cohen SJ, Stookey GK, Katz BP, Drook CA, Christen AG. Helping smokers quit: a randomized controlled trial with private practice dentists. J Am Dent Assoc. 1989;118(1):41-45.

16. Aligne CA, Moss ME, Auinger P, Weitzman M. Association of pediatric dental caries with passive smoking. JAMA. 2003;289(10):1258-1264.

17. Winickoff JP, Friebely J, Tanski SE, et al. Beliefs about the health effects of "thirdhand" smoke and home smoking bans. Pediatrics. 2009;123(1):e74-e79.

18. Matt GE, Quintana PJ, Hovell MF, et al. Households contaminated by environmental tobacco smoke: sources of infant exposures. Tob Control. 2004;13(1):29-37.

19. Northrup TF, Khan AM, Jacob P, et al. Thirdhand smoke contamination in hospital settings: assessing exposure risk for vulnerable paediatric patients. Tob Control. 2016;25(6):619-623.

20. Thomas JL, Hecht SS, Luo X, Ming X, Ahluwalia JS, Carmella SG. Thirdhand tobacco smoke: a tobacco-specific lung carcinogen on surfaces in smokers' homes. Nicotine Tob Res. 2014;16(1):26-32.

21. Drehmer JE, Ossip DJ, Rigotti NA, et al. Pediatrician interventions and thirdhand smoke beliefs of parents. Am J Prev Med. 2012;43(5):533-536.

22. Mcmillen RC, Winickoff JP, Klein JD, Weitzman M. US adult attitudes and practices regarding smoking restrictions and child exposure to environmental tobacco smoke: changes in the social climate from 2000-2001. Pediatrics. 2003;112(1 Pt 1):e55-e60.

23. Lando HA, Pirie PL, Hellerstedt WL, Mcgovern PG. Survey of smoking patterns, attitudes, and interest in quitting. Am J Prev Med. 1991;7(1):18-23.

24. Zhou X, Nonnemaker J, Sherrill B, Gilsenan AW, Coste F, West R. Attempts to quit smoking and relapse: factors associated with success or failure from the ATTEMPT cohort study. Addict Behav. 2009;34(4):365-373.

25. Groves RM, Cialdini RB, Couper MP. Understanding the decision to participate in a survey. Public Opin Q. 1992;56(4):475-495.

26. Cook C, Heath F, Thompson RL. A meta-analysis of response rates in Web- or Internet-based surveys. Educ Psychol Meas. 2000;60(6):821-836.

27. Yammarino FJ, Skinner SJ, Childers TL. Understanding mail survey response behavior: A meta-analysis. Public Opin Q. 1991;55(4):613-619.

28. Dillman DA, Smyth JD. Design effects in the transition to web-based surveys. Am J Prev Med. 2007;32(5 Suppl):S90-S96.

29. Klein JD. Incorporating effective smoking prevention and cessation counseling into practice. Pediatr Ann. 1995;24(12):646-652. 
Drug, Healthcare and Patient Safety

Dovepress

\section{Publish your work in this journal}

Drug, Healthcare and Patient Safety is an international, peer-reviewed open access journal exploring patient safety issues in the healthcare continuum from diagnostic and screening interventions through to treatment, drug therapy and surgery. The journal is characterized by the rapid reporting of reviews, original research, clinical, epidemiological and and educational programs across all areas of healthcare delivery. The manuscript management system is completely online and includes a very quick and fair peer-review system. Visit http://www.dovepress.com/ testimonials.php to read real quotes from published authors.

Submit your manuscript here: https://www.dovepress.com/drug-healthcare-and-patient-safety-journal 